\title{
ESTUDO DA PRODUTIVIDADE DA INDÚSTRIA MINEIRA E SEU DESEMPENHO DIANTE DA NACIONAL, NO PERÍODO DE 1996 A 2004
}

\section{STUDY OF THE PRODUCTIVITY OF MINAS GERAIS' INDUSTRY AND ITS PERFORMANCE AGAINST THE NATIONAL, BETWEEN 1996 AND 2004}

\author{
Marcelo Lacerda Rezende \\ Professor \\ Universidade Federal de Alfenas - UNIFAL-MG \\ Departamento de Ciências Exatas \\ R. Gabriel Monteiro da Silva, 700 \\ 37130-000 - Alfenas -MG \\ (35) 3299 1106/ 1110 - mrezende@ unifal-mg.edu.br \\ Felipe Moraes Cassin \\ Graduando em Administração \\ Universidade Federal de Itajubá - UNIFEI \\ Instituto de Engenharia de Produção e Gestão - IEPG \\ Rua Prefeito José Maria da Silveira Campos, 414 / Bairro Pinheirinho \\ 37500-200 - Itajubá - MG \\ (35) 3622-2029 - felipecassin@gmail.com
}

\begin{abstract}
RESUMO
O presente artigo estabelece um estudo comparativo da produtividade e da competitividade da indústria mineira diante da nacional, visando analisar o desempenho de Minas Gerais diante dos resultados da indústria nacional. Para isto, foram calculados três índices comportamentais para os principais gêneros industriais, com base nos dados de produção física, pessoal ocupado e salário médio para os anos de 1996, 2000 e 2004. Através deste estudo foi possível perceber que entre 1996 e 2000, o Estado de Minas Gerais se mostrou mais vulnerável às políticas econômicas do país, o que ocasionou uma diminuição de seu poder competitivo com relação ao restante do Brasil. No entanto, entre 2000 e 2004, a indústria mineira apresentou uma recuperação e ficou acima da média nacional. Também foi possível concluir que, no
\end{abstract}




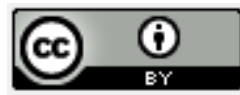

período analisado, as atividades com maior relevância para o Estado em termos de produção bruta foram os ramos de produtos alimentícios, bebidas e o setor de metalurgia básica.

Palavras-chave: Produtividade; Competitividade; Indústria; Minas Gerais.

\begin{abstract}
The present article carries out a comparative study of the productivity and competitiveness of Minas Gerais' industry against the national, with the goal of analyzing its performance. For this, there were established three behavioral indexes for the most important industrial branches, based on data related to physical production, occupied personnel and average wages for the years of 1996, 2000 and 2004. Through this study, it was possible to notice that, between 1996 and 2000, the state of Minas Gerais was more vulnerable to the national economic policies, what resulted in a decrease in its competitive power. However, between 2000 and 2004, Minas Gerais' industry presented a recovery and overcame the national average. It was also possible to conclude that the most relevant activities for the State's economy, in terms of Gross production, were those industrial branches related to the production of foodstuffs, beverages and basic metallurgy.
\end{abstract}

Key-words: Productivity; Competitiveness; Industry, Minas Gerais.

\title{
1. INTRODUÇÃO
}

Com o crescente aumento da competitividade entre os mercados e o estreitamento das relações, o crescimento sustentado da produtividade industrial passou a ser uma condição sine qua non para o bom desempenho de qualquer mercado. De acordo com Moreira (1994, p.2), produtividade é um conceito que está ligado à eficiência e à eficácia do sistema produtivo. Ou seja, medir a produtividade significa comparar a utilização dos insumos reais com aquilo que foi obtido a partir destes. Neste sentido, Silva (1988, p.14) define produtividade como o quociente entre a produção obtida por um dos fatores de produção.

O fato é que cada vez mais os mercados e as empresas neles inseridas buscam obter ganhos de produtividade para, consequentemente, obterem melhores condições de competir em escalas maiores. Segundo Contador (1996, p.3), os mercados precisam oferecer produtos com preços competitivos e isto requer que os custos de produção sejam cada vez menores. Além disso, o conceito de qualidade também vem sendo cada vez mais difundido visto que ele serve como fator decisório para os consumidores na hora de adquirir novos produtos.

Quando se pensa em competitividade, é importante lembrar que ela também ocorre em níveis regionais dentro dos mercados. Neste contexto, de acordo com Toyoshima \& Silva 


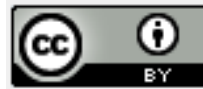

(2000, p.81), Minas Gerais possui uma posição estratégica na economia brasileira, não só por sua posição geográfica privilegiada, mas também por possuir um parque industrial moderno e uma grande infra-estrutura de ensino e pesquisa. Segundo Pordeus \& Lobato (2002, p.19), Minas Gerais ainda é beneficiada por possuir recursos naturais abundantes, uma forte base econômica na indústria cimenteira e minero-metalúrgica e uma liderança política bastante ativa. Ainda de acordo com os autores, o Estado possuía durante o período analisado no presente trabalho, um PIB equivalente a cerca de $10 \%$ do PIB nacional.

Desta forma, o presente trabalho tem como objetivo principal analisar a competitividade e a produtividade da indústria de Minas Gerais e comparar os resultados com o desempenho médio da indústria nacional. A análise será realizada para os anos compreendidos entre 1996 e 2004, período marcado por fortes transformações econômicas no país, principalmente no que se refere à adoção da política de paridade cambial do real com o dólar até meados de 1999.

Este artigo é composto de quatro seções, além desta introdução. Na seção 2, será discorrida a relação existente entre a competitividade e a produtividade, com base em conceitos e relacionamentos teóricos. Após traçar esta relação e sua importância, na seção 3 serão levantadas algumas políticas utilizadas para fomentar os níveis de produtividade tanto a nível macroeconômico (grandes mercados), quanto em nível microeconômico (empresas inseridas nestes mercados). Feitas estas considerações, o artigo passa então a focalizar seu objetivo principal: o estudo comparativo da produtividade e da competitividade da indústria mineira diante da nacional. Para isto serão utilizados dois indicadores comportamentais obtidos através de metodologia a ser descrita na seção 4. Por fim, na seção 5 serão tecidas considerações acerca dos resultados observados e, na seção 6, serão feitas as considerações finais.

\section{A RELAÇÃO ENTRE PRODUTIVIDADE E COMPETITIVIDADE}

De acordo com Moreira (1994, p.83), existem fortes mecanismos de ligação entre produtividade, competitividade, salários, preços e taxas de lucro. O estudo da produtividade industrial pode trazer benefícios não só para os mercados ou para as empresas neles inseridas como também para a sociedade em geral. Segundo Zaccareli (1990, p.12), a análise das empresas bem sucedidas, em especial as japonesas, revela a existência de uma forte relação 


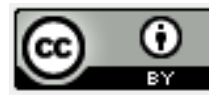

entre produtividade e a questão da vantagem competitiva. Portanto, tanto a nível macro quanto a nível micro, é possível obter maior vantagem competitiva através de estímulos ao aumento da produtividade. Azzoni \& Ferreira (1997, p.4) destacam que a competitividade regional de um mercado é o fator que guiará o processo da escolha locacional de novos investimentos industriais. Ou seja, um mercado ou uma região atrairá novos investimentos à medida de sua capacidade produtiva e de oferecer produtos e serviços que tenham ao mesmo tempo qualidade e preços competitivos. Segundo Silva (2004, p.3), o crescimento da produtividade industrial, ao reduzir o custo da produção e aumentar a sua escala, faz com que os produtos nacionais sejam comercializados com preços mais competitivos no mercado internacional. Silva (2004, p.3) argumenta que o aumento dos níveis de produtividade traz como benefícios a manutenção de preços baixos, a redução das taxas de juros e aumento do investimento e consumo. Além disso, o aumento da produtividade industrial ao reduzir o custo da produção e aumentar a sua escala, faz com que os produtos nacionais sejam comercializados com preços mais competitivos no comércio internacional.

Neste sentido, de acordo com Contador (1996, p.105), uma alta competitividade sempre vem acompanhada de uma redução dos custos totais, o que possibilita a oferta de produtos e serviços com preços mais competitivos. Ainda de acordo com o autor a produtividade industrial pode servir como arma para enfrentar a competição em termos de preço, produto, prazo e até mesmo pode beneficiar ou prejudicar a imagem da empresa ou do mercado como um todo. Para Azzoni \& Ferreira (1997, p.3), a competitividade regional pode revelar qual será o futuro das desigualdades regionais de um país. Segundo Haddad, Perobelli \& Santos (2004, p.1), a competitividade regional pode ser ainda mais acirrada do que a internacional, visto que a transferência de fatores e o fluxo de mercadorias entre estados de um país tende a ser maior do que entre países. Isto porque dentro de um mesmo país há um menor número de barreiras legais e uma maior proximidade geográfica, o que facilita o acesso a estes mercados. Portanto, pode-se aferir que as estruturas produtivas dos estados de um país são mais dependentes entre si do que as estruturas dos países. Ao formular políticas de desenvolvimento regional, portanto, é preciso conhecer essa interdependência. Dentro do escopo deste trabalho e considerando a afirmação de Haddad, Perobelli \& Santos (2004, p.3), a indústria mineira merece uma atenção especial no contexto da economia brasileira. Isso porque, historicamente, apresenta lucratividades muito acima das médias nacionais, o que faz com que as empresas mineiras estejam em uma posição altamente competitiva dentro do cenário nacional. 


\section{POLÍticas UTILIZADAS PARA SE OBTER AUMENTOS NA PRODUTIVIDADE}

De acordo com o exposto na seção anterior, o aumento dos índices de produtividade proporciona uma maior competitividade para as empresas. Portanto, torna-se coerente o levantamento de algumas políticas que podem ser utilizadas para estimular o aumento dos índices de produtividade. No entanto, é preciso separar os fatores que são válidos para a macro produtividade (grandes mercados) daqueles que influenciam a produtividade micro (empresas em geral), apesar de eles estarem diretamente relacionados.

\section{Macro Produtividade}

Na visão de Rossi Junior \& Ferreira (1999, p.01), os países que desejam garantir seu espaço no cenário internacional e que querem assegurar seu crescimento econômico devem estar freqüentemente atentos aos seus ganhos de produtividade. De acordo com Silva (1988, p.23), os principais fatores que influenciam a produtividade macro são a eficiência e o desperdício. Ou seja, para que um mercado consiga obter aumentos nos índices de produtividade seria ideal que houvesse um aumento da eficiência e que este fosse acompanhado de uma diminuição dos desperdícios. De acordo com o exposto, pode-se representar essa relação da seguinte forma:

$$
\text { Produtividade }=\underline{\text { Eficiência }}
$$

$$
\text { Desperdício }
$$

Uma análise da equação (1) permite aferir que um aumento do desperdício (denominador) ocasiona queda na produtividade. Ao mesmo tempo, um aumento da eficiência proporciona ganhos de produtividade. Neste sentido, a racionalização dos fatores pode ser uma técnica eficiente para se obter ganhos na produtividade macro. Segundo Swann (1977, p.5), a racionalização leva à redução dos custos de fabricação e, consequentemente, será um fator que influenciará diretamente o mercado como um todo.

O governo também pode adotar certas políticas, que de forma mais direta ou indireta, influenciarão o consumo e consequentemente a produtividade. Segundo Byrns \& Stone (1997, 


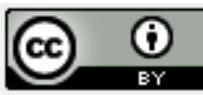

p.407), o governo pode fazer investimentos em infra-estrutura, tais como promover uma modernização das estradas, aumentar gastos com educação e fornecer maior assistência médica a população. Com este aumento dos gastos do governo, espera-se como consequiência direta que haja um aumento dos padrões de vida da população. Com isto as pessoas tendem a destinar uma maior parcela de suas rendas para o consumo de bens e serviços, fomentando assim o crescimento da economia.

De acordo com Pinho et al. (2004, p.449), outro fator que pode estimular (ou desestimular) a produtividade e, por conseguinte a competitividade, está relacionado com as taxas de câmbio. O mercado de câmbio (divisas) é formado pelos diversos agentes econômicos que compram e vendem moeda estrangeira, conforme suas necessidades. Quanto mais desvalorizada for a taxa de câmbio real, maior será a competitividade dos produtos domésticos frente aos produtos estrangeiros, o que amplia o número de exportações. Assim, para Rossetti (2003, p.895), as taxas de câmbio estabelecem ligações diretas entre os preços dos fatores de produção, mercadorias domésticas e os preços vigentes em outros países. Considerando os preços nacionais e internacionais em certo nível, um conjunto de baixas taxas de câmbio (com uma baixa cotação da moeda externa com relação à interna) prejudicará as exportações e estimulará as importações, o que provavelmente ocasionará um déficit no balanço de pagamentos.

Portanto, a taxa de câmbio possui um impacto direto na inserção da empresa no mercado externo. De acordo com Carvalho Júnior e Ruiz (2008) essa inserção externa, aliada a capacidade de inovação e economias de escopo e escala são fatores determinantes no desempenho das firmas brasileiras. Além disso, na década de 90, a redução das barreiras comerciais foi determinante para o aumento da produtividade média e saltos de produtividade em grande parte dos setores industriais brasileiros (FERREIRA e GUILLÉN, 2004).

De acordo com Kannebley Junior (2002, p.431), as políticas monetária, fiscal e cambial possuem um comportamento interdependente e passaram por diversas alterações no Brasil, visando à estabilização da inflação e a manutenção do equilíbrio externo da economia. Essas alterações envolveram mudanças de regimes cambiais e regras de condução e administração das taxas de câmbio e dos mercados cambiais. A partir de 1995, conseguiu-se a estabilização dos preços com a implementação do Plano Real. Nesta época foi introduzido o regime de bandas cambiais com o objetivo de incrementar a credibilidade da política cambial, por meio da adoção de medidas que implicavam maior estabilidade da taxa de câmbio real e o padrão de variação da taxa nominal de câmbio. Em janeiro de 1999 a manutenção deste 
regime tornou-se insustentável para o governo brasileiro, que resolveu adotar um regime de taxas de câmbio flexíveis, o que gerou uma sensível desvalorização das taxas de câmbio nominal e real. A política de paridade cambial adotada pelo governo entre 1994 e 1999 trouxe diversas conseqüências para a economia brasileira. Se por um lado ela possibilitou a modernização da indústria, por outro lado a entrada de produtos estrangeiros no país com preços altamente competitivos fez com que os produtos nacionais enfrentassem uma competição mais acirrada com os produtos importados. De acordo com Lemos (2002, p.42), a economia mineira foi mais sensível a esta política do que os outros estados brasileiros.

Byrns \& Stone (1997, p.403) ressaltam ainda uma ferramenta que o governo dispõe e que é de extrema importância dentro do contexto analisado: as taxas de juros. As firmas inseridas nos mercados demandam o crédito dos bancos para financiarem o estoque de capital necessário à realização de seus projetos. Considerando-se agentes racionais e firmas maximizadoras de lucro, dado que o custo de oportunidade de uma unidade marginal do estoque de capital é dado pela taxa de juros, uma condição necessária para a maximização dos lucros é que a produtividade marginal do capital seja igual ou superior ao seu custo de oportunidade, no caso, a taxa de juros. Uma vez que a produtividade marginal dos fatores de produção é decrescente, podemos aferir que uma taxa de juros menor implicará em um estoque de capital ótimo mais elevado. Com o intuito de adquirir um aumento no estoque de capital essa firma passará então a demandar mais crédito.

Taxas de juros mais baixas estimulam a obtenção de empréstimos. Como consequiência, os gastos tanto por parte dos consumidores quanto por parte dos investidores tende a aumentar. Taxas de juros mais elevadas tornam o investimento menos atrativo para investidores potenciais, que neste caso, precisarão recorrer a empréstimos. Quando se aumenta a taxa de juros, o Banco Central eleva o custo de captação da firma, reduzindo sua capacidade de endividamento e, com isto, suas possibilidades de fazer despesas de investimento (BLANCHARD, 2004, p.72).

\section{Produtividade Micro}

Como o intuito desta seção é apenas apresentar um panorama geral sobre as principais ferramentas utilizadas para fomentar os níveis de produtividade nas empresas, limitou-se a discorrer sobre os Programas de Participação nos Lucros ou Resultados, 
ferramenta amplamente utilizada na atualidade. O uso dessa ferramenta tem surtido efeitos em muitas empresas onde foi aplicado.

Os Programas de Participação nos Lucros ou Resultados Passados ganham ainda mais importância com a observação, a partir do trabalho de Souza Netto e Curado (2005), do crescimento negativo dos salários na segunda metade da década de 90 , em torno de $-0,6 \%$ ao ano. Isso evidencia que, embora a produtividade do trabalho e os salários tenham sido crescentes na primeira fase da década, existiram fatores incidentes sobre essas variáveis que acabaram por distanciar suas trajetórias.

De acordo com Pinho et al. (2004, p.101), a visão micro focaliza as empresas que estão inseridas no mercado, suas respectivas produções e custos, enquanto que a visão macro interessa-se pelos agregados como a produção e o consumo do mercado como um todo. Elas estão diretamente relacionadas, visto que o desempenho econômico de um mercado também é influenciado pelo desempenho das empresas que neles estão inseridas. Portanto, é cabível o levantamento de algumas técnicas que podem influenciar a produtividade e a competitividade das empresas.

A preocupação com os fatores que podem fomentar um aumento da produtividade nas empresas não é algo novo. Os questionamentos acerca das circunstâncias que motivariam os funcionários de uma empresa a produzirem mais já foram abordados por inúmeras formas desde a Teoria Clássica da Administração no século XIX. Taylor (1986, p.112) defendia a idéia de que os funcionários são principalmente movidos por aspectos financeiros e, que portanto, a produtividade só poderia ser obtida por meio de aumentos salariais grandes e constantes. Já Fayol (1994, p.61) defendia que só surgiria um comprometimento com a organização por parte dos funcionários caso estes fossem tratados com benevolência e justiça por parte da Administração (eqüidade). Ele ainda defendia a idéia de que a produtividade poderia ser obtida através de uma rígida hierarquia de centralização.

Apesar de muitas destas idéias já serem consideradas ultrapassadas, elas já continham algumas noções sobre uma das técnicas mais eficazes utilizadas atualmente pelas empresas: o programa de participação nos lucros ou resultados. De acordo com Buhler (2000, p.3), para motivar um funcionário a aumentar seus níveis de produtividade o administrador precisa saber reconhecer o comportamento apropriado e, mais do que isto, saber como recompensar este comportamento. Desta forma, a implementação de uma participação dos funcionários nos lucros ou resultados das empresas pode representar uma fonte de maximização da eficácia organizacional. De acordo com Corrêa e Lima (2006), a evidência 


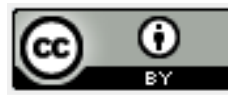

empírica internacional sobre efeitos de esquemas de participação dos trabalhadores nos lucros e resultados das empresas oferece indícios de que esses esquemas podem melhorar os indicadores das empresas que os adotam e as relações no ambiente de trabalho.

Existem diversas modalidades de participação nos resultados. Os funcionários podem participar do faturamento, dos aumentos nas receitas, dos ganhos de produtividade, dos lucros e até mesmo da propriedade da empresa. A participação também pode ser obtida através de comissões sobre vendas, salários adicionais por resultados ou atingimento de metas, entre tantas outras formas. (MAXIMIANO, 1997, p.336)

A Participação nos Lucros ou Resultados tem sido utilizada com sucesso em muitas organizações, como é o caso da Mercedes-Benz do Brasil, da SNR, do Unibanco, da Sadia, da ABB Group e de tantas outras. Apesar das vantagens, a implantação de um Programa de Participação nos Resultados (PPR) também se revela como um outro grande desafio para as empresas que optam por esta estratégia. Isto porque é preciso saber qual a melhor forma de recompensar os funcionários e, ao mesmo tempo, agir com transparência.

Ainda de acordo com Maximiano (1997, p.333), a Administração Participativa revela-se como uma nova tendência e, neste sentido, a formação de equipes auto-gerenciadas tem sido cada vez mais utilizada nas empresas, visando proporcionar um certo grau de autonomia para os funcionários.

Vale lembrar que existem diversas teorias sobre a motivação dentro das empresas. Várias técnicas diferentes são utilizadas para motivar os funcionários e consequentemente aumentar os níveis de produtividade.

\section{METODOLOGIA}

Para analisar a competitividade e a produtividade da indústria mineira diante da nacional, foram calculados três índices comportamentais para os anos de 1996, 2000 e 2004, com base nos dados de Produção Bruta, Pessoal Ocupado e Salário Médio Real, todos eles obtidos por meio da Pesquisa Industrial Anual (PIA) realizada pelo Instituto Brasileiro de Geografia e Pesquisa (IBGE, 2006). O valor bruto da Produção Bruta é dado pela soma das vendas de produtos e serviços industriais (receita líquida industrial), variação dos estoques dos produtos acabados e em elaboração, e produção própria realizada para o ativo imobilizado. O Pessoal Ocupado consiste no número de pessoas ocupadas em cada ramo no 


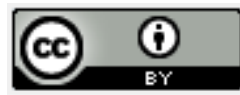

último dia do ano a que se refere, independentemente de terem ou não vínculo empregatício. Por fim, o Salário Médio Real é obtido através da divisão entre as importâncias pagas durante o ano (salários, bonificações, honorários, comissões sobre vendas, $13^{\circ}$ salário, etc.) e o número de pessoas que receberam estes pagamentos, ou seja, o pessoal ocupado.

Através destes dados, referentes aos anos pesquisados, é possível calcular indicadores que permitem analisar e comparar a competitividade e a produtividade da economia mineira diante da nacional. O cálculo destes indicadores segue a mesma metodologia utilizada por Toyoshima e Silva (2000, p.84), que procuraram avaliar o desempenho da produção, da produtividade e do poder competitivo do Estado de Minas Gerais em relação ao Brasil para os períodos 1985-1989 e 1989-1996.

O primeiro índice calculado foi a produtividade média do trabalho (PT) para cada gênero "n" e para cada ano observado "t". Este índice consiste na divisão entre a produção bruta e o pessoal ocupado e é calculado para Minas Gerais e para o Brasil por meio das equações (2) e (3):

PTnt $M G=\underline{\text { Produção Bruta para o gênero } \mathrm{n} \text { durante o ano t em Minas Gerais }}$

Pessoal Ocupado para o gênero n, durante o ano t em Minas Gerais

PTnt $\mathrm{BR}=\underline{\text { Produção Bruta para o gênero } \mathrm{n} \text { durante o ano t no Brasil }}$

Pessoal Ocupado para o gênero n, durante o ano t no Brasil

Após calcular a produtividade média do trabalho é possível analisar a competitividade da economia mineira através do ICMnt (Índice Relativo de Custo Unitário da Mão de Obra), uma vez que esse indicador possibilita a identificação dos ramos da indústria mineira que estão ganhando ou perdendo poder competitivo ao longo do tempo. Se este índice diminui ao longo do tempo, pode-se dizer que está havendo ganhos de poder competitivo, pois os custos com a mão de obra estão crescendo menos do que a produtividade do trabalho. De forma análoga, se este índice aumenta, pode-se dizer que está ocorrendo uma perda de poder competitivo, pois os custos de mão de obra estão crescendo mais do que a produtividade do trabalho. $\mathrm{O}$ indicador de competitividade potencial é calculado a partir da equação (4):

$\mathrm{ICMnt}=\underline{(\mathrm{Wnt} M G / \mathrm{Wnt} \mathrm{BR})}$ 
Sendo: Wnt MG = salário médio real pago em Minas Gerais no ano "t", gênero "n";

Wnt BR = salário médio real pago no Brasil no ano "t", gênero "n";

PTnt MG = produtividade média do trabalho em Minas Gerais, no ano " $\mathrm{t}$ ", gênero "n";

PTnt BR = produtividade média do trabalho no Brasil no ano " $\mathrm{t}$ ", gênero "n".

O terceiro e último indicador calculado foi o Índice Relativo de Produtividade do Trabalho (IPT). Este indicador possibilita a identificação dos gêneros da indústria de Minas Gerais que apresentaram aumento ou redução de produtividades entre os anos 1996-2000 e 2000-2004, comparativamente àquele aumento ou redução observado na indústria brasileira. O cálculo pode ser feito através da equação (6):

$$
\mathrm{IPTnt}=\underline{\text { PTnt MG }}
$$

Sendo:

PTnt MG, a produtividade média do trabalho, em Minas Gerais, para o gênero "n" no ano " $\mathrm{t}$ "

PTnt BR, a produtividade média do trabalho, no Brasil, para o gênero "n" no ano "t".

\section{RESULTADOS E DISCUSSÃO}

\section{Análise do Índice Relativo do Custo Unitário de Mão de Obra (ICM)}

Após o cálculo dos indicadores é possível analisar o desempenho deles ao longo do período analisado. Para verificar o comportamento da competitividade potencial de Minas Gerais diante da brasileira (ICMnt) entre 1996 e 2000, tomou-se o ano de 1996 como base. Após isto, foram calculadas as variações ocorridas entre o ano base e o ano de 2000 (vide anexo I). Para verificar o comportamento do indicador de competitividade entre 2000 e 2004, tomou-se o ano de 2000 como base (vide anexo II).

Entre os anos de 1996 e 2000 é possível perceber que a indústria mineira perdeu poder competitivo em 17 ramos com relação ao mercado brasileiro. A perda do poder aquisitivo, nesse período, pela indústria mineira, também foi observada por Lemos (2002, 


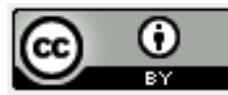

p.42), que a considera resultado da adoção da política de paridade cambial do real com o dólar entre os anos de 1994 e 1999. A utilização desta política, segundo esse autor, fez com que houvesse uma efetiva substituição relativa da produção industrial interna pela produção externa importada. Neste contexto a economia mineira foi mais afetada do que a nacional como um todo. Além disso, os custos de produção da indústria mineira elevaram-se para níveis acima da média nacional, ficando acima dos níveis de produtividade, o que também contribuiu para que o Estado perdesse poder competitivo dentro do mercado nacional. De acordo com Prochnik \& Vaz (2002, p.135) é preciso ressaltar que o final da década de 90 não foi um período profícuo para a economia brasileira como um todo, visto que ela cresceu lentamente. Além destes fatores, há de destacar o efeito negativo que a precariedade das malhas rodoviárias exercem sobre a produtividade da indústria mineira. Segundo César (2002, p.15), é facilmente constatável que uma infra-estrutura de transporte deficiente é capaz de reduzir a produtividade e deteriorar a qualidade de vida da população.

Dentre todos os ramos analisados no presente trabalho, a atividade que mais perdeu competitividade em Minas Gerais com relação ao Brasil entre 1996 e 2000 foi a fabricação dos produtos de fumo (121,36\%). Segundo Gonçalves et al. (2003, p.95), a indústria do fumo apresentou, portanto um comportamento contrário às séries anteriores, já que esta vinha apresentando ganhos de produtividade e competitividade. A indústria do fumo teve uma queda de 53,67\% em sua produção bruta entre 1996 e 2000, e o mesmo aconteceu com o pessoal ocupado em sua produção.

Ao se realizar a comparação das variações entre 2000 e 2004 (vide anexo 2), observa-se que o Estado de Minas Gerais voltou a apresentar um ganho de poder competitivo em comparação à média nacional. O gênero que mais ganhou competitividade no Estado foi a fabricação de máquinas para escritório e equipamentos de informática (82,10\%). Apesar da recuperação do Estado em geral, diversos ramos perderam competitividade tais como o de produtos do fumo (que continuou perdendo poder competitivo), extração de minerais nãometálicos, confecção de artigos do vestuário e acessórios, fabricação de produtos de couro e madeira, fabricação de celulose e produtos de papel, produtos de minerais não-metálicos, fabricação de produtos de metal, reciclagem, entre outros.

A comparação do indicador de competitividade para todo o período analisado entre 1996 e 2004 (vide anexo 3), revela que, como um todo, este período foi favorável para a economia mineira (ganho de 1,98\%), apesar das perdas observadas no período entre 1996 e 2000. Através dos indicadores é possível perceber que o período compreendido entre 1996 e 


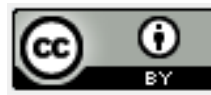

2000 foi de perda competitiva para o Estado de Minas Gerais com relação ao Brasil, mas que esta relação se inverteu no segundo período analisado, quando o Estado obteve um ganho competitivo maior que a média nacional. Dentro deste contexto alguns ramos de atividades apresentaram exatamente este comportamento: de queda de poder competitivo no primeiro período e uma recuperação no segundo. Dentre eles, destaca-se o desempenho do ramo de produção de máquinas para escritório e equipamentos de informática. No ano de 2000, comparativamente a 1996, o ramo apresentou uma perda de 105,35\% em seu poder competitivo diante do Brasil. Já entre 2000 e 2004, este setor apresentou uma considerável recuperação, com um aumento competitivo $82,1 \%$ diante da média nacional.

Algumas atividades apresentaram ganhos de competitividade sucessivos (durante os dois períodos observados), como é o caso da fabricação de produtos químicos, metalurgia básica e das indústrias extrativas como um todo, em especial a de extração de minerais metálicos e também o ramo de edição, impressão e reprodução de gravações. Da mesma forma que estes ramos apresentaram desempenho cada vez mais competitivo, houve alguns gêneros que apresentaram um comportamento de perda de competitividade tanto no ano de 2000 quanto em 2004 com relação ao ano de 1996. Dentre eles, os que obtiveram as maiores perdas foram: fabricação de equipamentos de transporte $(76,28 \%$ no primeiro período e $15,36 \%$ no segundo), máquinas e materiais elétricos (20,83\% no primeiro período e $6,26 \%$ no segundo), produtos de madeira $(24,75 \%$ no primeiro período e $0,71 \%$ no segundo), produtos de metal $(15,86 \%$ no primeiro e $5,33 \%$ no segundo), dentre outros.

Considerando os ramos das indústrias de transformação, durante todos os períodos observados, as atividades com maior relevância em termos de produção bruta em Minas Gerais são aquelas que envolvem a fabricação de produtos alimentícios, bebidas e o setor de metalurgia básica. No ano de 2004, por exemplo, a produção de alimentos e bebidas correspondia a $16,91 \%$ de toda a produção bruta do estado e a metalurgia básica tinha uma participação ainda maior, de 26,10\% da produção total. Apesar de tamanha relevância durante todos os anos observados, o ramo de produtos alimentícios e bebidas apresentou uma perda de poder competitivo em 2000, comparativamente a $1996(10,10 \%)$, porém assim como as outras atividades em geral, este setor apresentou uma recuperação $(3,58 \%)$ entre 2000 e 2004 . A indústria da metalurgia básica obteve ganhos de poder competitivo em ambos os períodos analisados (2,27\% no primeiro período e $0,07 \%$ no segundo).

É importante ressaltar que apesar da perda de vantagem competitiva do estado de Minas Gerais com relação ao Brasil entre 1996 e 2000 (2,61\%), houve um aumento de 


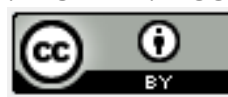

$165,36 \%$ da produção bruta total e de 108,49\% do pessoal ocupado na produção. Entre 2000 e 2004, período em que o Estado ganhou poder competitivo diante da economia brasileira, observou-se um aumento de $214,38 \%$ da produção bruta total mineira, que também foi acompanhado por um aumento no número de pessoas ocupadas na produção.

\section{Análise do Índice Relativo de Produtividade do Trabalho (IPT)}

Uma análise do comportamento do Índice Relativo de Produtividade do Trabalho confirma os resultados apresentados com a análise do Índice Relativo do Custo Unitário de Mão de Obra. Ou seja, os resultados obtidos apontam um desempenho da indústria de Minas Gerais inferior à média nacional, entre 1996 e 2000, e a recuperação do Estado no período seguinte (vide anexos IV e V). Conforme mencionado, o indicador IPT compara a produtividade do trabalho de cada gênero da indústria de Minas Gerais com relação ao desempenho médio de cada gênero da indústria nacional.

A comparação entre 1996 e 2000 evidencia que, neste período, os níveis de produtividade da indústria de Minas Gerais foram inferiores em 4,3\% quando comparados à média nacional. Tal constatação só vem confirmar o que pôde ser percebido através do indicador de competitividade, ou seja, a existência de uma maior vulnerabilidade do Estado diante das políticas econômicas adotadas pelo Governo Federal naquele período.

Através da análise do IPT também foi possível identificar os ramos que apresentaram as maiores reduções: fabricação de máquinas para escritório e equipamentos de informática $(60,56 \%)$, produtos do fumo $(46,16 \%)$ e fabricação de coque, refinos de petróleo e combustíveis $(33,36 \%)$. Durante este período o único ramo que apresentou uma variação positiva na participação de Minas Gerais na indústria brasileira foi a fabricação de material eletrônico e de aparelhos e equipamentos de comunicações.

Entre 2000 e 2004, a análise do IPT revela que Minas Gerais obteve uma significativa melhora nos seus níveis de produtividade e obteve resultados superiores em $6,34 \%$ com relação à média nacional. Dentre os ramos que apresentaram variações positivas, destaca-se a fabricação de máquinas para escritório e equipamentos de informática, o qual reverteu o desempenho decadente e apresentou um ganho de 729,61\%. Outros gêneros que contribuíram para o desempenho global positivo do Estado neste período foram edição, 
impressão e reprodução de gravações $(13,51 \%)$, equipamentos hospitalares e de automação industrial $(15,75 \%)$ e fabricação de produtos alimentícios e bebidas $(10,41 \%)$.

\section{CONCLUSÃO}

O objeto de estudo do presente artigo foi a comparação do desempenho da produtividade e da competitividade da indústria mineira diante da indústria nacional como um todo. Estudos dessa natureza mostram-se bastante úteis dentro do atual contexto econômico, já que o estreitamento das relações entre os mercados exige que estes estejam cada vez mais preparados para competir em escalas cada vez maiores. Além disto, a questão da produtividade e da competitividade reflete a capacidade de um mercado fabricar bens, produtos e serviços a preços competitivos. Neste sentido, para que um mercado seja de fato competitivo, faz-se necessária uma busca por alternativas que possam incrementar a sua produtividade. Além disso, é essencial que as empresas neles inseridas sejam capazes de produzir em maior quantidade sem que para isto haja necessariamente um aumento nos seus custos.

Uma vez que a competitividade ocorre externamente e internamente, pode-se concluir que os Estados mais competitivos em termos de produtividade são beneficiados, pois tendem a absorver um maior número de investimentos industriais. Comparando o desempenho de Minas Gerais com a média nacional foi possível perceber que o Estado possui uma posição de destaque e altamente competitiva dentro do cenário nacional, porém mostrouse mais vulnerável diante das políticas adotadas pelo governo federal entre 1996 e 2000 . No entanto, sua produtividade que vinha apresentando um comportamento decadente no primeiro período analisado, apresentou uma recuperação no segundo período analisado e voltou a ficar acima da média nacional.

Apesar das oscilações e de sua vulnerabilidade diante das políticas econômicas do país, Minas Gerais apresenta-se como uma economia altamente competitiva dentro do cenário nacional, sendo um Estado privilegiado por sua posição estratégica e também por seus recursos naturais abundantes. Dentro desse contexto, sugere-se a realização de trabalhos que tenham como objetivo aprofundar o estudo dos fatores que fizeram com que Minas Gerais tenha sido mais vulnerável diante das políticas econômicas adotadas em parte dos anos 90 . 
Estudos dessa natureza poderão contribuir para a adoção de políticas que empeçam a perda da competitividade pelas indústrias do estado.

Por fim, deve-se lembrar que o presente estudo abrangeu o período de 1996 a 2004. As mudanças ocorridas na conjuntura econômica, em especial na taxa de câmbio, a partir de 2004 podem ter tido um significativo efeito sobre o cenário estudado. Assim, novas análises a partir de 2004 poderão dar uma importante contribuição para o entendimento da competitividade do estado de Minas Gerais.

\section{REFERÊNCIAS}

AZZONI, C. R.; FERREIRA, D. A. Competitividade regional e reconcentração industrial: o futuro das desigualdades regionais no Brasil. São Paulo: USP, 1997.

BLANCHARD, O. Macroeconomia. 3 Ed. São Paulo: Prentice-Hall, 2004

BUHLER, P. M. Managing in the new millennium. Burlington, EUA: Supervision, vol.3, 2000 .

BYRNS, R. I. \& STONE, G. W. Macroeconomia. São Paulo: Makron, 1997. 511p.

CARVALHO JÚNIOR, N. S. de; RUIZ, R.M. Determinantes do desempenho das firmas a partir das novas capacitações internas: um estudo de firmas brasileiras. Revista de Economia Contemporânea, Rio de Janeiro, v.12, n.1, p.97-127, 2008.

CÉSAR, R. V.; Transporte e Logística. In: et al. Minas Gerais do Século XXI: Infraestrutura: Sustentando o Desenvolvimento. Belo Horizonte: Rona Editora, 2002.

CONTADOR, J. C. Modelo para aumentar a Competitividade Industrial: a transição para a gestão participativa. Editora Edgard Blucher, 1996. 364p.

CORREA, D., LIMA, G. T. Participação dos trabalhadores nos lucros e resultados das empresas: lições da experiência internacional. Revista de Economia Contemporânea, v.10, n.2, 2006, p.357-388.

FAYOL, H. Administração Industrial e Geral. 10. ed. São Paulo: Atlas, 1994. 138p.

FERREIRA, P. C.; GUILLEN, O. T. de C. Estrutura competitiva, produtividade industrial e liberalização comercial no Brasil. Revista Brasileira de Economia, v.58, n.4, 2004, p.507-532. 


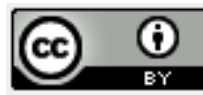

GONÇALVES et al. Competitividade Industrial de Minas Gerais no período 1985-2000: um enfoque econométrico. Nova Economia, Belo Horizonte, v.10, n. 1, p.81-108, jul.dez.2003.

HADDAD, E. A; PEROBELli, F. S.; SANTOS, R. A. C. Análise Estrutural da Inserção Econômica de Minas Gerais. Belo Horizonte: UFMG, 2004.

INSTITUTO BRASILEIRO DE GEOGRAFIA E ESTATISTICA (IBGE) - Pesquisa Industrial anual. Disponível em <www.ibge.gov.br>. Acesso em: 28 mai. 2006.

KANNEBLEY JUNIOR, S. Desempenho exportador brasileiro recente e taxa de câmbio real: uma análise setorial. Revista Brasileira de Economia, Rio de Janeiro, v.56, n. 3, p. 429456, jul./set. 2002.

LEMOS, M. B. Estrutura e Dinâmica. In: et al. Minas Gerais do Século XXI: Integrando a Indústria para o futuro. Belo Horizonte: Rona Editora, 2002.

MAXIMIANO, A. Teoria Geral da Administração. 7. ed. São Paulo: Atlas, 1997. 371p.

MOREIRA, D. Os benefícios da Produtividade Industrial. 1. ed. São Paulo: Pioneira, 1994. $108 \mathrm{p}$.

PINHO, D. B., et al. Manual de Economia. 5. ed. São Paulo: Saraiva, 2004. 606 p.

PORDEUS, I. A.; LOBATO, P.L. Minas Gerais do Século XXI: Uma visão do novo desenvolvimento. Belo Horizonte: Rona Editora, 2002.

PROCHNIK, V.; VAZ, B. O. Cadeias Produtivas Relevantes. In: LEMOS, M. B. et al. Minas Gerais do Século XXI: Integrando a Indústria para o futuro. Belo Horizonte: Rona Editora, 2002.

ROSSETTI, J. P. Introdução à Economia. 20. ed. São Paulo: Atlas, 2003. 922 p.

ROSSI JÚNIOR, J. L.; FERREIRA, P. C. Evolução da Produtividade Industrial Brasileira e Abertura Comercial. Rio de Janeiro: IPEA/FGV, 1999.

SILVA, D. B. L. O Impacto da Abertura Comercial sobre a Produtividade da Indústria Brasileira. São Paulo: FGV, 2004.

SILVA, V. J. L. da. Princípios de Produtividade. Rio de Janeiro: Técnica, 1988. 87p.

SOUZA NETTO, C. R. de; CURADO, M. L. Produtividade do trabalho, salários reais e desemprego na indústria de transformação do Brasil na década de 1990: teoria e evidência. Revista de Economia Contemporânea, v.9, n.3, p. 485-508, 2005.

SWANN, K. Técnicas de Aumento da Produtividade. Rio de Janeiro: Livraria Interciência, 1977. 195p. 
TAYLOR, F. W. Princípios da Administração Científica. 7. ed. São Paulo: Atlas, 1986. $134 \mathrm{p}$.

TOYOSHIMA, S. H.; SILVA, M. P. da. Competitividade e produtividade: uma análise comparativa do desempenho industrial de Minas Gerais, 1985-1996. Nova Economia, Belo Horizonte, v.10, n. 1, p.79-107, jul.2000.

ZACCARELli, S. B. Administração Estratégica da Produção. São Paulo: Atlas, 1990. $134 \mathrm{p}$. 


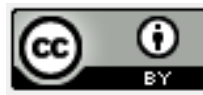

ANEXO I - Índice Relativo de Custo de Mão de Obra Unitário 1996-2000 (Base: $1996=100 \%$ )

\begin{tabular}{|c|c|c|}
\hline & \\
\hline & 1996 & 2000 \\
\hline Total & $100,00 \%$ & $102,61 \%$ \\
\hline C Indústrias extrativas & $100,00 \%$ & $83,63 \%$ \\
\hline 10 Extração de carvão mineral & $100,00 \%$ & - \\
\hline 11 Extração de petróleo e serviços relacionados & $100,00 \%$ & - \\
\hline 13 Extração de minerais metálicos & $100,00 \%$ & $94,16 \%$ \\
\hline 14 Extração de minerais não-metálicos & $100,00 \%$ & - \\
\hline D Indústrias de transformação & $100,00 \%$ & $108,30 \%$ \\
\hline 15 Fabricação de produtos alimentícios e bebidas & $100,00 \%$ & $110,10 \%$ \\
\hline 16 Fabricação de produtos do fumo & $100,00 \%$ & $221,31 \%$ \\
\hline 17 Fabricação de produtos têxteis & $100,00 \%$ & $102,06 \%$ \\
\hline 18 Confecção de artigos do vestuário e acessórios & $100,00 \%$ & $100,34 \%$ \\
\hline $\begin{array}{l}19 \text { Preparação de couros e fabricação de artefatos de couro, } \\
\text { artigos de viagem e calçados }\end{array}$ & $100,00 \%$ & $117,67 \%$ \\
\hline 20 Fabricação de produtos de madeira & $100,00 \%$ & $124,35 \%$ \\
\hline 21 Fabricação de celulose, papel e produtos de papel & $100,00 \%$ & $65,59 \%$ \\
\hline 22 Edição, impressão e reprodução de gravações & $100,00 \%$ & $90,45 \%$ \\
\hline $\begin{array}{l}23 \text { Fabricação de coque, refino de petróleo, elaboração de } \\
\text { combustíveis nucleares e produção de álcool }\end{array}$ & $100,00 \%$ & $116,79 \%$ \\
\hline 24 Fabricação de produtos químicos & $100,00 \%$ & $90,63 \%$ \\
\hline 25 Fabricação de artigos de borracha e plástico & $100,00 \%$ & $104,31 \%$ \\
\hline 26 Fabricação de produtos de minerais não-metálicos & $100,00 \%$ & $94,56 \%$ \\
\hline 27 Metalurgia básica & $100,00 \%$ & $97,73 \%$ \\
\hline $\begin{array}{l}28 \text { Fabricação de produtos de metal - exceto máquinas e } \\
\text { equipamentos }\end{array}$ & $100,00 \%$ & $115,86 \%$ \\
\hline 29 Fabricação de máquinas e equipamentos & $100,00 \%$ & $126,00 \%$ \\
\hline $\begin{array}{l}30 \text { Fabricação de máquinas para escritório e equipamentos de } \\
\text { informática }\end{array}$ & $100,00 \%$ & $205,35 \%$ \\
\hline 31 Fabricação de máquinas, aparelhos e materiais elétricos & $100,00 \%$ & $120,83 \%$ \\
\hline $\begin{array}{l}32 \text { Fabricação de material eletrônico e de aparelhos e } \\
\text { equipamentos de comunicações }\end{array}$ & $100,00 \%$ & $84,80 \%$ \\
\hline $\begin{array}{l}33 \text { Fabricação de equipamentos de instrumentação médico- } \\
\text { hospitalares, instrumentos de precisão e ópticos, equipamentos } \\
\text { para automação industrial, cronômetros e relógios }\end{array}$ & $100,00 \%$ & $111,39 \%$ \\
\hline $\begin{array}{l}34 \text { Fabricação e montagem de veículos automotores, reboques } \\
\text { e carrocerias }\end{array}$ & $100,00 \%$ & $121,79 \%$ \\
\hline 35 Fabricação de outros equipamentos de transporte & $100,00 \%$ & $176,28 \%$ \\
\hline 36 Fabricação de móveis e indústrias diversas & $100,00 \%$ & $102,64 \%$ \\
\hline 37 Reciclagem & $100,00 \%$ & $96,47 \%$ \\
\hline Outros & $100,00 \%$ & 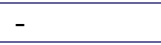 \\
\hline
\end{tabular}

\footnotetext{
Fonte: Elaboração Própria a partir de dados do IBGE (2006)
} 


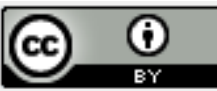

ANEXO II - Índice Relativo de Custo de Mão de Obra Unitário 2000-2004 (Base: $2000=100 \%$ )

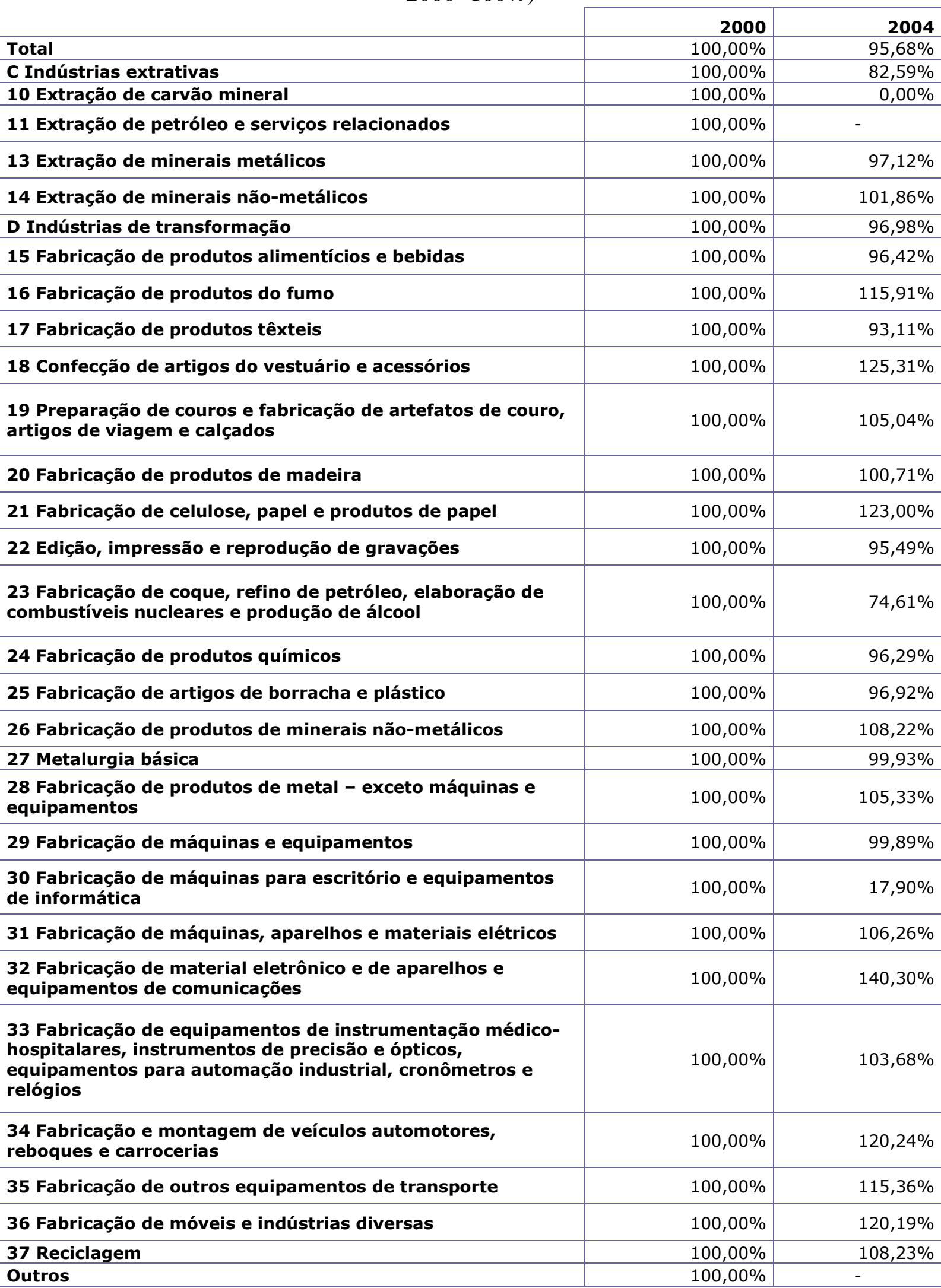

Fonte: Elaboração Própria a partir de dados do IBGE (2006) 


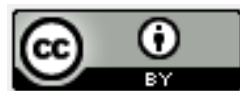

ANEXO III - Índice Relativo de Custo de Mão de Obra Unitário 1996-2004 (Base:

\begin{tabular}{|c|c|c|c|}
\hline & 1996 & 2000 & 2004 \\
\hline Total & $100 \%$ & $102,61 \%$ & $98,18 \%$ \\
\hline C Indústrias extrativas & $100 \%$ & $83,63 \%$ & $69,07 \%$ \\
\hline 10 Extração de carvão mineral & $100 \%$ & - & - \\
\hline 11 Extração de petróleo e serviços relacionados & $100 \%$ & - & - \\
\hline 13 Extração de minerais metálicos & $100 \%$ & $94,16 \%$ & $91,45 \%$ \\
\hline 14 Extração de minerais não-metálicos & $100 \%$ & - & - \\
\hline D Indústrias de transformação & $100 \%$ & $108,30 \%$ & $105,03 \%$ \\
\hline 15 Fabricação de produtos alimentícios e bebidas & $100 \%$ & $110,10 \%$ & $106,16 \%$ \\
\hline 16 Fabricação de produtos do fumo & $100 \%$ & $221,31 \%$ & $256,51 \%$ \\
\hline 17 Fabricação de produtos têxteis & $100 \%$ & $102,06 \%$ & $95,03 \%$ \\
\hline 18 Confecção de artigos do vestuário e acessórios & $100 \%$ & $100,34 \%$ & $125,74 \%$ \\
\hline $\begin{array}{l}19 \text { Preparação de couros e fabricação de artefatos } \\
\text { de couro, artigos de viagem e calçados }\end{array}$ & $100 \%$ & $117,67 \%$ & $123,60 \%$ \\
\hline 20 Fabricação de produtos de madeira & $100 \%$ & $124,35 \%$ & $125,23 \%$ \\
\hline 21 Fabricação de celulose, papel e produtos de papel & $100 \%$ & $65,59 \%$ & $80,67 \%$ \\
\hline 22 Edição, impressão e reprodução de gravações & $100 \%$ & $90,45 \%$ & $86,37 \%$ \\
\hline $\begin{array}{l}23 \text { Fabricação de coque, refino de petróleo, } \\
\text { elaboração de combustíveis nucleares e produção de } \\
\text { álcool }\end{array}$ & $100 \%$ & $116,79 \%$ & $87,14 \%$ \\
\hline 24 Fabricação de produtos químicos & $100 \%$ & $90,63 \%$ & $87,26 \%$ \\
\hline 25 Fabricação de artigos de borracha e plástico & $100 \%$ & $104,31 \%$ & $101,10 \%$ \\
\hline $\begin{array}{l}26 \text { Fabricação de produtos de minerais não- } \\
\text { metálicos }\end{array}$ & $100 \%$ & $94,56 \%$ & $102,33 \%$ \\
\hline 27 Metalurgia básica & $100 \%$ & $97,73 \%$ & $97,67 \%$ \\
\hline $\begin{array}{l}28 \text { Fabricação de produtos de metal - exceto } \\
\text { máquinas e equipamentos }\end{array}$ & $100 \%$ & $115,86 \%$ & $122,05 \%$ \\
\hline 29 Fabricação de máquinas e equipamentos & $100 \%$ & $126,00 \%$ & $125,86 \%$ \\
\hline $\begin{array}{l}30 \text { Fabricação de máquinas para escritório e } \\
\text { equipamentos de informática }\end{array}$ & $100 \%$ & $205,35 \%$ & $36,76 \%$ \\
\hline $\begin{array}{l}31 \text { Fabricação de máquinas, aparelhos e materiais } \\
\text { elétricos }\end{array}$ & $100 \%$ & $120,83 \%$ & $128,39 \%$ \\
\hline $\begin{array}{l}32 \text { Fabricação de material eletrônico e de aparelhos } \\
\text { e equipamentos de comunicações }\end{array}$ & $100 \%$ & $84,80 \%$ & $118,98 \%$ \\
\hline $\begin{array}{l}33 \text { Fabricação de equipamentos de instrumentação } \\
\text { médico-hospitalares, instrumentos de precisão e } \\
\text { ópticos, equipamentos para automação industrial, } \\
\text { cronômetros e relógios }\end{array}$ & $100 \%$ & $111,39 \%$ & $115,48 \%$ \\
\hline $\begin{array}{l}34 \text { Fabricação e montagem de veículos automotores, } \\
\text { reboques e carrocerias }\end{array}$ & $100 \%$ & $121,79 \%$ & $146,43 \%$ \\
\hline 35 Fabricação de outros equipamentos de transporte & $100 \%$ & $176,28 \%$ & $203,36 \%$ \\
\hline 36 Fabricação de móveis e indústrias diversas & $100 \%$ & $102,64 \%$ & $123,36 \%$ \\
\hline 37 Reciclagem & $100 \%$ & $96,47 \%$ & $104,41 \%$ \\
\hline Outros & $100 \%$ & - & - \\
\hline
\end{tabular}

Fonte: Elaboração Própria a partir de dados do IBGE (2006) 
ANEXO IV - Índice Relativo de Produtividade do Trabalho 1996-2000 (Base: 1996=100\%)

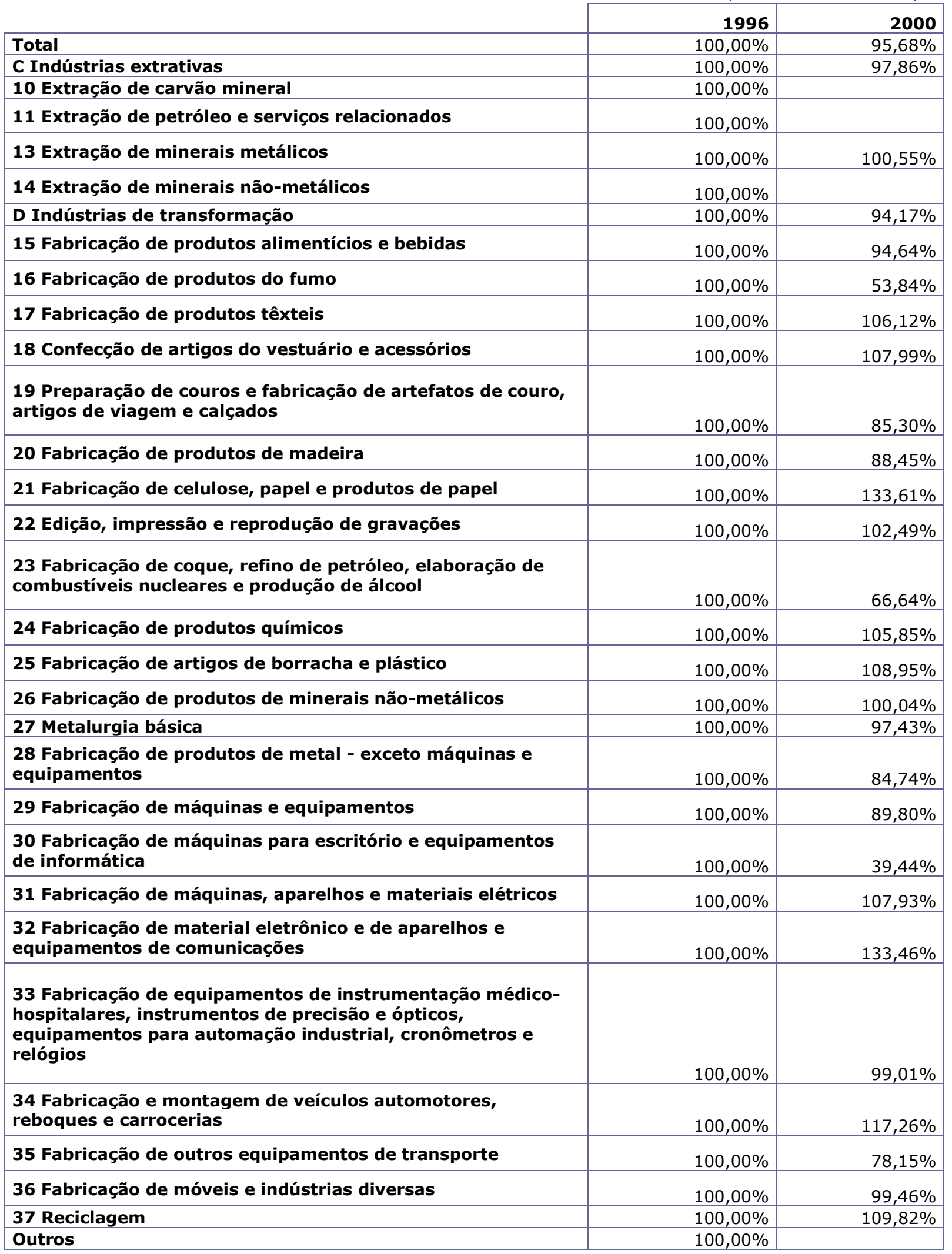

Fonte: Elaboração Própria a partir de dados do IBGE (2006) 
ANEXO V - Índice Relativo de Produtividade do Trabalho 2000-2004 (Base: 2000=100\%)

\begin{tabular}{|c|c|c|}
\hline & 2000 & 2004 \\
\hline Total & $100,00 \%$ & $106,34 \%$ \\
\hline C Indústrias extrativas & $100,00 \%$ & $94,21 \%$ \\
\hline 10 Extração de carvão mineral & $100,00 \%$ & $0,00 \%$ \\
\hline 11 Extração de petróleo e serviços relacionados & $100,00 \%$ & \\
\hline 13 Extração de minerais metálicos & $100,00 \%$ & $97,19 \%$ \\
\hline 14 Extração de minerais não-metálicos & $100,00 \%$ & $101,88 \%$ \\
\hline D Indústrias de transformação & $100,00 \%$ & $106,47 \%$ \\
\hline 15 Fabricação de produtos alimentícios e bebidas & $100,00 \%$ & $110,41 \%$ \\
\hline 16 Fabricação de produtos do fumo & $100,00 \%$ & $92,35 \%$ \\
\hline 17 Fabricação de produtos têxteis & $100,00 \%$ & $99,99 \%$ \\
\hline 18 Confecção de artigos do vestuário e acessórios & $100,00 \%$ & $96,20 \%$ \\
\hline $\begin{array}{l}19 \text { Preparação de couros e fabricação de artefatos de couro, } \\
\text { artigos de viagem e calçados }\end{array}$ & $100,00 \%$ & $83,88 \%$ \\
\hline 20 Fabricação de produtos de madeira & $100,00 \%$ & $88,18 \%$ \\
\hline 21 Fabricação de celulose, papel e produtos de papel & $100,00 \%$ & $76,25 \%$ \\
\hline 22 Edição, impressão e reprodução de gravações & $100,00 \%$ & $113,51 \%$ \\
\hline $\begin{array}{l}23 \text { Fabricação de coque, refino de petróleo, elaboração de } \\
\text { combustíveis nucleares e produção de álcool }\end{array}$ & $100,00 \%$ & $124,92 \%$ \\
\hline 24 Fabricação de produtos químicos & $100,00 \%$ & $87,12 \%$ \\
\hline 25 Fabricação de artigos de borracha e plástico & $100,00 \%$ & $93,22 \%$ \\
\hline 26 Fabricação de produtos de minerais não-metálicos & $100,00 \%$ & $112,01 \%$ \\
\hline 27 Metalurgia básica & $100,00 \%$ & $106,06 \%$ \\
\hline $\begin{array}{l}28 \text { Fabricação de produtos de metal - exceto máquinas e } \\
\text { equipamentos }\end{array}$ & $100,00 \%$ & $96,20 \%$ \\
\hline 29 Fabricação de máquinas e equipamentos & $100,00 \%$ & $107,72 \%$ \\
\hline $\begin{array}{l}30 \text { Fabricação de máquinas para escritório e equipamentos } \\
\text { de informática }\end{array}$ & $100,00 \%$ & $189,61 \%$ \\
\hline 31 Fabricação de máquinas, aparelhos e materiais elétricos & $100,00 \%$ & $103,98 \%$ \\
\hline $\begin{array}{l}32 \text { Fabricação de material eletrônico e de aparelhos e } \\
\text { equipamentos de comunicações }\end{array}$ & $100,00 \%$ & $40,67 \%$ \\
\hline $\begin{array}{l}33 \text { Fabricação de equipamentos de instrumentação médico- } \\
\text { hospitalares, instrumentos de precisão e ópticos, } \\
\text { equipamentos para automação industrial, cronômetros e } \\
\text { relógios }\end{array}$ & $100,00 \%$ & $115,75 \%$ \\
\hline $\begin{array}{l}34 \text { Fabricação e montagem de veículos automotores, } \\
\text { reboques e carrocerias }\end{array}$ & $100,00 \%$ & $78,26 \%$ \\
\hline 35 Fabricação de outros equipamentos de transporte & $100,00 \%$ & $58,06 \%$ \\
\hline 36 Fabricação de móveis e indústrias diversas & $100,00 \%$ & $84,71 \%$ \\
\hline 37 Reciclagem & $100,00 \%$ & $92,78 \%$ \\
\hline Outros & $100,00 \%$ & \\
\hline
\end{tabular}

Fonte: Elaboração Própria a partir de dados do IBGE (2006) 